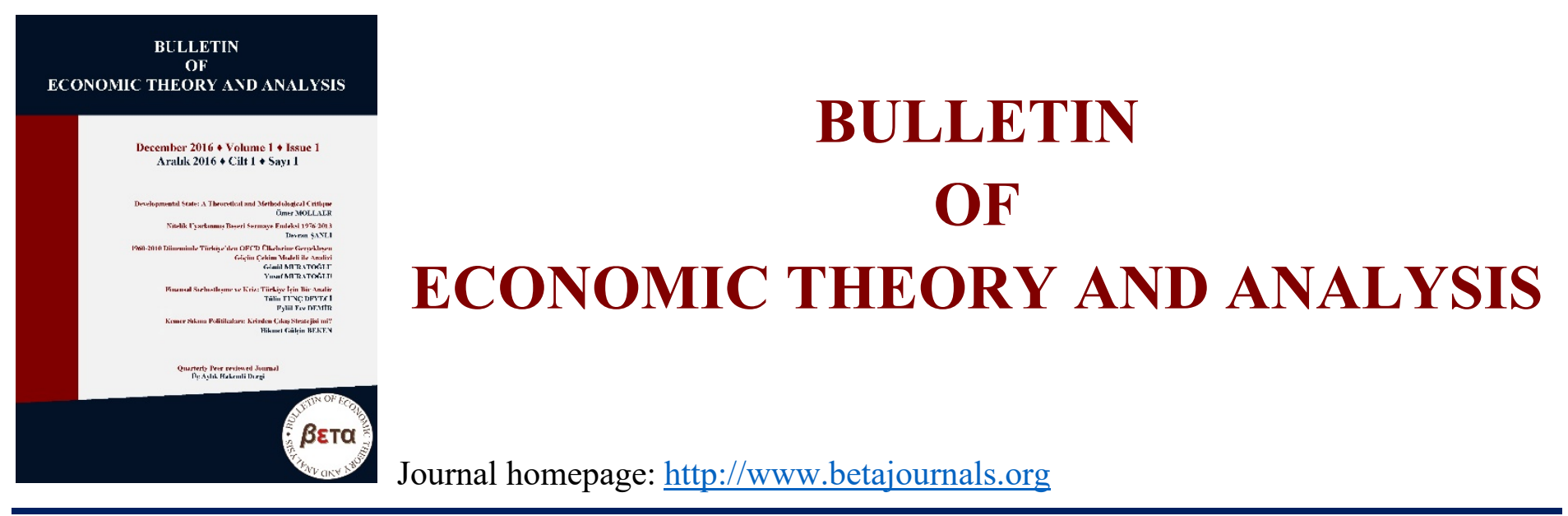

\title{
Yatırım ve Finansman Politikalarının Finansal Performansa Etkisi: Borsa İstanbul Üzerine Ekonometrik Bir Araştırma
}

\section{Emre Esat TOPALOĞLU ๑ https://orcid.org/0000-0001-8771-779X}

\section{Zekiye AKGÜÇ @ https://orcid.org/0000-0001-5083-364X}

To cite this article: Topaloğlu, E., E., \& Akgüç, Z. (2021). Yatırım ve Finansman Politikalarının Finansal Performansa Etkisi: Borsa İstanbul Üzerine Ekonometrik Bir Araştırma. Bulletin of Economic Theory and Analysis, 6(2), 55-77.

Received: 07 Sep 2021

Accepted: 26 Oct 2021

Published online: 31 Dec 2021

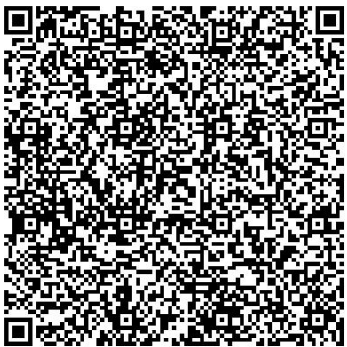




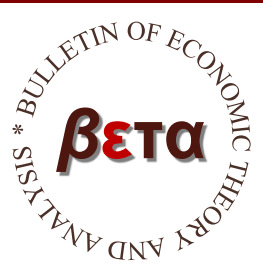

\title{
Bulletin of Economic Theory and Analysis
}

Volume VI, Issue 2, pp. 55-77, 2021

http://www.betajournals.org

Original Article / Araştırma Makalesi

Received / Alınma: 07.09.2021 Accepted / Kabul: 26.10.2021

\section{Yatırım ve Finansman Politikalarının Finansal Performansa Etkisi: Borsa İstanbul Üzerine Ekonometrik Bir Araştırma}

\author{
Emre Esat TOPALOĞLU ${ }^{\mathrm{a}}$ \\ Zekiye AKGÜÇ ${ }^{b}$ \\ ${ }^{\mathrm{a}}$ Doç. Dr., Şırnak Üniversitesi, İ̈BF, Finans ABD, Şırnak, TÜRKIYE \\ (D) https://orcid.org/ 0000-0001-8771-779X \\ ${ }^{b}$ Yüksek Lisans Mezunu, Şırnak Üniversitesi, Lisansüstü Eğitim Enstitüsü, Şırnak, TÜRKIYYE \\ (h https://orcid.org/0000-0001-5083-364X \\ ÖZ \\ Çalışmada, Borsa İstanbul (BİST) 100 endeksinde işlem gören firmalarda çalışma \\ sermayesi yönetiminin finansal performansa olan etkisinin ortaya çıkarılması \\ hedeflenmiş̧ir. Söz konusu hedefin gerçekleştirilmesi amacıyla, BIST100 Endeksinde \\ 2005-2018 yılları arasında kesintisiz işlem gören 16 firmanın verileri panel veri \\ yöntemi ile analiz edilmiştir. Analiz aşamasında aktif karlılık oranı ve özsermaye \\ karlılığı esas alınarak iki model oluşturulmuştur. Analiz sonucunda, Model 1'de \\ yatırım politikası ile aktif karlılık arasında anlamlı ve pozitif ilişki tespit edilirken, \\ finansman politikası ile aktif karlılık arasında ise negatif yönlü ilişki tespit edilmiştir. \\ Model 2'de ise, özsermaye karlılığı ile yatırım politikası arasında pozitif yönlü ilişki \\ belirlenirken, finansman politikası ile özsermaye karlılığı arasında anlamlı herhangi bir \\ ilişki tespit edilememiştir. \\ Anahtar Kelimeler \\ Panel Veri Analizi, \\ Finansal \\ Performans, \\ Çalışma Sermayesi \\ Politikalar1, \\ Borsa İstanbul \\ JEL Kodu \\ C23, D53, G32
}

ÍLETIŞiM Emre Esat TOPALOĞLU® emresatopal@hotmail.com $\risingdotseq$ a Doç. Dr., Şırnak Üniversitesi, İktisadi ve İdari Bilimler Fakültesi, Finans ABD, Şırnak, TÜRKIYYE

* Bu çalışma birinci yazar tarafından Şırnak Üniversitesi Lisansüstü Eğitim Enstitüsü’nde tamamlanmış "Çalışma Sermayesi Yönetiminin Finansal Performansa Etkisi: Borsa İstanbul 100 Endeksinde Faaliyet Gösteren Firmalar Üzerine Uygulama" adlı yüksek lisans tezinden yararlanılarak hazırlanmıştır. 


\section{Impact of Investment and Financial Policies on Financial Performance: An Econometric Research on the Borsa Istanbul}

\begin{abstract}
In this study, it was aimed to determine the effect of working capital management on financial performance by using the data of companies traded in the BIST 100 index. BIST 100 index was examined by panel data analysis method using data from 14 years periods of 16 companies that traded continuously 2005-2018. In the study, two models were specified based on the return on assets and return on equity. As a result of the analysis in Model 1, while the positive relationship was determined between investment policy and return on asset; a negative relationship was determined between financing policies and return on asset. In Model 2, while the positive relationship was determined between investment policy and return on equity, there is no relationship between financing policy and return on equity.
\end{abstract}

Keywords

Panel Data Analysis,

Financial

Performance,

Working Capital

Policies,

Borsa İstanbul

JEL Classification C23, D53, G32

\section{Giriş}

Günümüz koşullarında firmalar arasında yaşanan rekabet yoğunluğu ve özellikle kriz dönemlerinde yaşanılan ekonomik ve finansal sıkıntılar doğrultusunda firmalarda fon sağlama ve yatırım ufku önem kazanmaktadır. Firmalar, yeterli seviyede çalışma sermayesi ile karlılık seviyelerini yükseltebilmekte ve piyasalardaki faaliyetlerini daha etkin bir şekilde sürdürebilmektedirler. Çalışma sermayesi, mal veya hizmetlerin üretiminden başlayarak satılıp gelir elde edilmesine kadar geçen süreçte, üretim faktörlerine bağlanan fonlar olarak ifade edilebilmektedir (Aksoy ve Yalçıner, 2008:5). Firmaların faaliyetlerini başarılı bir şekilde yürütebilmesi, yatırımlarını yönetebilmesi ve istikrarlı bir şekilde büyüyebilmesi için çalışma sermayesi yönetimi son derece önemli bir faktör olarak karşımıza çıkmaktadır (Korkmaz ve Ceylan, 2008:296). Çalışma sermayesi yönetimi ayrıca firmaların finansal performanslarının artmasında ve rekabet avantajı sağlayabilmelerinde de önem bir rol oynayabilmektedir. Çalışma sermayesinde ortaya çıkabilecek olan sorunlar firma karlılığını etkileyebilir ve hatta finansal dengeyi alt üst de edebilmektedir. Bu nedenle çalışma sermayesi yönetimi finansal performansa etkisinin araştırılması gerekmektedir (Kendirli ve Çankaya, 2016:47).

Çalışma sermayesi yönetimi, firmaların kısa vadeli yatırım kararlarını kapsamaktadır. Dönen varlıklara yapılacak olan yatırım seviyesi ve dönen varlıkların finansmanı ile ilgili alınan 
tüm kararlar çalışma sermayesi politikası olarak tanımlanmaktadır. Bu yatırım kararlarında finansman politikalarının dikkate alınması ve yönetilmesi firmalarda karlılı̆̆ı artırabilmektedir (Coşkun ve Kök, 2011:75). Bir firmada toplam varlıkların dönen varlıklarına oranı çalışma sermayesi yatırım politikasını, bu varlıkların ne kadarının kısa vadeli kaynaklarla finanse edilmesi gerektiği ise çalışma sermayesi finansman politikasını oluşturmaktadır (Nazir ve Afza, 2009:25). Firmalarda, çalışma sermayesinin iyi bir şekilde planlanması ve kontrol edilmesi gerekmektedir (Eljelly, 2004:48).

Firma yöneticileri için faaliyetlerin yürütülmesi açısından, yatırımcılar, kredi veren kurum ve kuruluşlar, araştırmacılar tarafından finansal performansın göstergesi olan karlılı̆̆ın ekonomik olarak önemli sonuçlar doğurduğunu ortaya koymaktadır. Çalışma sermayesi yönetiminin finansal performansın göstergesi olan karlılığa olan etkisi, farklı endüstri ve dönemler doğrultusunda hem akademik hem de finans yöneticileri ve araştırmacıları açısından önemli ve güncel bir konu niteliğindedir.

Bu çalışmada, 2005-2018 döneminde BIST 100 Endeksinde kesintisiz olarak faaliyet gösteren firmalarda çalışma sermayesi yönetimi ile finansal performans arasındaki ilişki panel veri analizi yöntemi ile analiz edilmiştir. Çalışma beş bölümden oluşmaktadır. Giriş bölümünde çalışma sermayesine yönelik teorik açıklamalara değinilmiştir. İkinci bölümde ulusal ve uluslararası literatürde konuya ilişkin yapılmış çalışmalara yer verilmiştir. Üçüncü bölümde veri seti, model ve yöntem ile ilgili açıklamalar yapılmıştır. Dördüncü bölümde panel veri analizi sonucunda elde edilen bulgular açıklanırken son bölümde ise ulaşılan bulgular neticesinde sonuçlar ve daha sonraki çalışmalara ilişkin önerilere yer verilmiştir. Bu çalışmanı, araştırma kapsamında seçilen firmalar, incelenen dönem ve çalışmaya yönelik elde edilen sonuçlar doğrultusunda literatüre katkı sağladığı düşünülmektedir.

\section{Literatür Taraması}

Çalışma sermayesi yönetiminin finansal performansa etkisine dair ulusal ve uluslararası literatürde çeşitli çalışmalar bulunmaktadır. Bu çalışmalardan bazılarına dair elde edilen bulgular kronolojik bir şekilde aşağıda sunulmuştur.

Filbeck \& Krueger (2005) yaptıkları çalışmada, 1996-2000 yıllarını kapsayan ABD’de faaliyette bulunan 32 şirketin, çalışma sermayesi yatırım ve finansman politikalarının endüstrilere 
göre değişkenlik gösterip göstermediğini incelemiştir. Çalışma sonucunda, çalışma sermayesi politikalarının sektörlere göre değişkenlik gösterdiği sonucuna ulaşılmıştır.

Lazaridis \& Tryfonidis (2006), Atina Borsası'nda 2001-2004 dönemini esas alarak yaptıkları çalışmada, çalışma sermayesi yönetimi ile firma karlılı̆̆ arasındaki ilişkinin anlamlı ve negatif yönlü bir ilişki olduğu tespit etmişlerdir.

Salawu (2007), 1994-2003 yılları arasında Nijerya Borsası'nda işlem gören 42 firmanın atılgan ve muhafazakâr çalışma sermayesi politikaları arasındaki uzun süreli ilişkiyi araştırmıştır. Çalışma sonucunda, çalışma sermayesi yatırım politikalarında önemli derecede farklılık görüldüğ̈̈; atılgan yatırım politikasını izleyen firmaların, varlıkların yönetimi açısından ihtiyatlı finansman politikasını kullanması gerektiği sonucuna ulaşılmışıtır.

Şamiloğlu \& Demirgüneș (2008) çalışmalarında, 1998-2007 dönemlerinde İMKB'de faaliyet gösteren üretim firmalarının çalışma sermayesi yönetiminin firma karlılığına olan etkisini incelemişlerdir. Analiz sonucunda, çalışma sermayesi yönetimi ile karlılık oranı arasında negatif yönlü bir ilişkinin olduğu sonucuna varılmıştır.

Nazir \& Afza (2009), Pakistan Karaçi Menkul Kıymetler Borsasında 1998-2005 yıllarında faaliyet gösteren 204 firmanın çalışma sermayesi yatırım ve finansman politikaları ile firma karlılığı arasındaki ilişkiyi incelemişlerdir. Araştırma neticesinde, çalışma sermayesi finansman ve yatırım politikalarından biri olan agresif politikası ile karlılık arasında negatif yönlü bir ilişki tespit edilmiştir.

Raheman vd. (2010) çalışmalarında, Pakistan Karaçi borsasında 1998-2007 yıllarında faaliyetine kesintisiz olarak devam eden 204 imalat şirketinin çalışma sermayesi yönetiminin firma performansına etkisi olup olmadığını araştırılarak; koruyucu politikayı önemseyen firmaların tahsilât ve ödeme politikaları üzerinden performanslarını arttırmalarına yönelik odaklanmaları gerektiği sonucuna varılmıştır.

Al-Shubiri (2011) ise 2004-2008 yıllarında Ürdün Amman borsasında kayıtlı olan 14 banka ve 59 sanayi firmasının çalışma sermayesi saldırgan ve koruyucu politikaları ile karlılık ve risk arasındaki ilişkiyi incelemiştir. Çalışmada, çalışma sermayesi yatırım ve finansman politikaları ile karlılık arasında ters yönlü bir ilişki tespit edilmiştir. 
Şahin (2011), Türkiye'de imalat firmalarının 2005-2010 dönemindeki çalışma sermayesi yatırım ve finansman politikalarının firma performansı üzerindeki etkisini panel veri analizi yöntemini kullanarak araştırmıştır. Çalışma neticesinde, firmaların performanslarını arttırabilmeleri için finansal kriz ve krizin olmadığı dönemlerde ihtiyatlı çalışma sermayesi yatırım ve finansman politikalarını önemsemelerinin firmalar açısından daha faydalı olacağı sonucuna ulaşılmıştır.

Taani (2012) tarafından yapılan çalışmada, 45 şirketin çalışma sermayesi politikalarının finansal performans üzerindeki etkisini belirlemeyi hedeflemiştir. Araştırma sonucunda, çalışma sermayesi politikası ile özsermaye karlılığı ve aktif karlılık oranı arasında bir ilişki belirlenememiştir.

Makori \& Jagongo (2013) çalışmalarında, 2003-2012 döneminde Kenya'da bulunan Nairobi Menkul Kıymetler Borsası'nda faaliyet gösteren 5 inşaat ve imalat firmasının çalışma sermayesi yönetimi ile firma performansı arasındaki ilişkinin incelenmesi amaçlanmıştır. Çalışma sonucunda, karlılık ile borç ödeme süresi ve stok devir hızı arasında pozitif; ortalama tahsil süresi ile nakit süresi arasında negatif ilişki olduğu belirlenmiştir.

Mwangi vd. (2014), Kenya Nairobi Menkul Kiymetler Borsası'nda 2006-2012 y1llarında faaliyet gösteren 42 firmanın çalışma sermayesi yönetiminin firma performansı üzerindeki etkisini analiz etmişlerdir. Analiz sonucunda, agresif finansman politikasının aktif karlılık ile özkaynak karlılığı arasında anlamlı bir ilişki tespit edilmiştir. Muhafazakâr yatırım politikası ile firma performansı arasında pozitif bir ilişki olduğu saptanmıştır. Çalışmada, firmaların yöneticileri agresif finansman politikası benimseyen firmalar performanslarını artırmak için muhafazakâr yatırım politikasını kullanmaları gerektiğini ortaya koymuşlardır.

Wanguu (2015) tarafından yapılan çalışmada, Nairobi Menkul Kıymetler Borsası'nda 2010-2014 yılları arasında yer alan 38 firmanın agresif çalışma sermayesi politikalarının karlılık üzerindeki etkisi araştırılmıştır. Agresif finansman politikası ile karlılık arasında negatif yönde anlamlı bir ilişki olduğu sonucuna varılmıştır.

Bhatia \& Srivastava (2016), 2000-2014 yıllarını kapsayan Hindistan'daki Bombay Borsası'nda faaliyet gösteren 179 firmanın çalışma sermayesi yönetimi ile firma performansı arasındaki ilişkiyi araştırmışlardır. Elde edilen bulgular sonucunda, çalışma sermayesi yönetimi ile firma performansı arasında negatif yönlü bir ilişki tespit edilmiştir. 
Tripathi \& Ahamed (2017) tarafından yapılan çalışmada, 2000-2014 yıllarında Hindistan Ulusal Menkul Kıymetler Borsası'nda kesintisiz işlem gören firmaların çalışma sermayesi yönetiminin finansal performans üzerindeki etkisinin incelenmesi amaçlanmıştır. Analiz sonucunda, çalışma sermayesinin ile finansal performans arasında anlamlı ve negatif yönlü bir ilişki olduğu sonucuna ulaşılmıştır.

Rasyid (2017) çalışmasında, 2014 yılında 393 Endonezya firmasının agresif çalışma sermayesi politikasının firma karlılığı ve değeri üzerindeki etkisini incelemiştir. Çalışma sonucunda, agresif çalışma sermayesi politikasının firma karlılığı etkilediği, ancak piyasa değerini etkilemediği sonucuna varılmıştır. Ayrıca, agresif yatırım politikası ile firma karlılı̆̆ı arasında pozitif bir ilişkisi tespit edilirken, agresif finansman politikası ile firma karlılığı arasında ise negatif ilişki tespit edilmiştir.

Öndeş \& Pagheh (2018), 2009-2016 yılları arasında BIST’te işlem gören 123 firmanın çalışma sermayesi finansman ve yatırım stratejileri ile pay senedi getirisi, karlık ve risk arasındaki ilişkiyi incelemişlerdir. Araştırmada, firmaların yatırım stratejisi ile karlılıkları arasında pozitif; finanslama stratejisi ile negatif ilişkinin varlığı ortaya çıkarılmıştır.

Nur Topaloğlu (2019) tarafından yapılan çalışmada, 2010-2018 döneminde BİST 30 endeksinde faaliyette bulunan 14 firmanın çalışma sermayesi yatırım ve finansman politikaları ile firma karlılığı arasındaki ilişki araştırılmıştır. Araştırma sonucunda, çalışma sermayesi yatırım politikası ile net kâr marjı ve aktif karlılık arasında anlamlı pozitif yönlü bir ilişki belirlenirken; çalışma sermayesi finansman politikası ile özsermaye karlılı̆̆ı, aktif karlılık oranı ve net kar marjı arasında anlamlı negatif yönlü bir ilişki tespit edilmiştir.

Çalışma sermayesi ile finansal performans arasındaki ilişkinin incelendiği çalışmalar genel olarak değerlendirildiğinde finansman politikası ile finansal performans arasında negatif, yatırım politikası ile ise pozitif bir ilişki içerisinde olduğu söylenebilir. Dolayısıyla çalışmada, reel sektör firmalarının yatırım ve finansman politikalarının da bu yönde bir ilişki içerisinde olması beklenmektedir. Çalışmanın kapsamı ve oluşturulan modeller doğrultusunda literatüre katkı sağlandığı ve özgünlük sunduğu düşünülmektedir. 


\section{Yöntem}

Araştırmada 2005-2018 dönemine ait BİST 100 Endeksinde kesintisiz olarak faaliyetlerini sürdüren 16 firmanın çalışma sermayesi yönetiminin finansal performans üzerindeki etkisinin belirlenmesi amaçlanmaktadır. Araştırmaya, hizmet kuruluşları, holdingler, aracı kurum ve kuruluşlar, yatırım ortaklıkları, bankalar, sigorta kuruluşları dâhil edilmemiştir. Firmalara ilişkin veriler Borsa İstanbul (www.bist.gov.tr.) ve Kamuyu Aydınlatma Platformu (http://www.kap.gov.tr) (KAP) veri tabanlarından elde edilmiştir. Araştırmaya konu olan firmalar, Tablo 1'de gösterilmiştir.

Tablo 1

Çalışmada Kullanılan Firmalar

\begin{tabular}{lll}
\hline Sıra & BİST Kodu & Firma Adı \\
\hline 1 & ANACM & ANADOLU CAM SANAYİ A.Ş. \\
2 & ARCLK & ARÇELIK A.Ş. \\
3 & ASELS & ASELSAN ELEKTRONIKK SANAYİ VE TİCARET A.Ş. \\
4 & EREGL & EREĞLİ DEMİR VE ÇELİK FABRIKKALARI T.A.Ş. \\
5 & FROTO & FORD OTOMOTIV SANAYİ A.Ş. \\
6 & IPEKE & İPEK DOĞAL ENERJI KAYNAKLARI ARAŞTIRMA VE ÜRETİM \\
7 & KOZAA & AŞ. \\
8 & KRDMD & KOZA ANADOLU METAL MADENCİLİK İŞLETMELERİ A.Ş. \\
9 & SASA & KARDEMİR KARABÜK DEMİR ÇELİK SANAYİ VE TİCARET A.Ş. \\
10 & SODA & SASA POLYESTER SANAYİ A.Ş. \\
11 & TOASO & SODA SANAYİ A.Ş. \\
12 & TRKCM & TOFAŞ TÜRK OTOMOBİL FABRİKASI A.Ş. \\
13 & TUPRS & TRAKYA CAM SANAYİİ A.Ş. \\
14 & ULKER & TÜPRAŞ-TÜRKIYYE PETROL RAFINERİLERİ A.Ş. \\
15 & VESTL & ÜLKER BİSKÜVİ SANAYİ A.Ş. \\
16 & YATAS & VESTEL ELEKTRONIK SANAYİ VE TİCARET A.Ş. \\
& & YATAŞ YATAK VE YORGAN SANAYİ VE TİCARET A.Ş. \\
\hline
\end{tabular}

Kaynak. Borsa İstanbul ve Kamuyu Aydınlatma Platformu verileri ile oluşturulmuştur.

Araştırmada, finansal performansın ölçütü olarak aktif karlılık ve özsermaye karlılığ bağımlı değişkenler olarak belirlenirken, çalışma sermayesi ise yatırım ve finnansman politikası bağımsız değişkenleri ile temsil edilmektedir. Araştırma modelini oluşturan değişkenlere ilişkin hesaplamalar ve k1saltmalar Tablo 2'de sunulmuştur. 
Tablo 2

Değişkenler ve Hesaplamalar

\begin{tabular}{lll}
\hline $\begin{array}{l}\text { Bağımlı Değişkenler } \\
\text { Değişken }\end{array}$ & Hesaplamalar & Kısaltmalar \\
\hline $\begin{array}{l}\text { Aktif Karlılık } \\
\text { Özsermaye Karlılığı }\end{array}$ & (Net Dönem Karı / Toplam Aktifler) & ROA (Return on Asset) \\
\hline Bağımsım Değişkenler Karı / Özsermaye) & ROE (Return on Equity) \\
\hline Yatırım Politikası & (Dönen Varlıklar/ Toplam Varlıklar) & IP (Investing Policy) \\
Finansman Politikası & (Kısa Vadeli Yabancı Kaynaklar/ Toplam & FP (Financial Policy) \\
& Varlıklar) & \\
\hline
\end{tabular}

Çalışmada kullanılan bağımlı değiş̧kenler; Lazaridis \& Tryfonidis (2006), Şamiloğlu \& Demirgüneş (2008), Taani (2012), Tripathi \& Ahamed (2017), Makori \& Jagongo (2013), bağımsız değişkenler ise; Nazir \& Afza (2009) Raheman vd. (2010), Öndeş \& Pagheh (2018), Salawu, (2007), Wanguu (2015), Al-shubira (2011), Mwangi vd. (2014), tarafından yapılan çalışmalar esas alınarak belirlenmiştir. Çalışmada kullanılan değiş̧enler doğrultusunda araştırmada oluşturulan hipotezler aşağıdaki gibidir.

\section{Hipotez 1}

$\mathrm{H}_{0}$ : BIST 100 firmalarında finansman politikası ile aktif karlılık arasında bir ilişki yoktur.

$\mathrm{H}_{1}$ : BIST 100 firmalarında finansman politikası ile aktif karlılık arasında bir ilişki vardır.

\section{Hipotez 2}

H0: BIST 100 firmalarında yatırım politikası ile aktif karlılık arasında bir ilişki yoktur. H1: BIST 100 firmalarında yatırım politikası ile aktif karlılık arasında bir ilişki vardır.

\section{Hipotez 3}

H0: BIST 100 firmalarında finansman politikası ile özsermaye karlılığı arasında bir ilişki yoktur. H1: BIST 100 firmalarında finansman politikası ile özsermaye karlılığı arasında bir ilişki vardır.

\section{Hipotez 4}

H0: BIST 100 firmalarında yatırım politikası ile özsermaye karlılığı arasında bir ilişki yoktur.

H1: BIST 100 firmalarında yatırım politikası ile özsermaye karlıı̆̆ı arasında bir ilişki vardır.

Çalışma sermayesi yönetimin finansal performansa etkisini belirleyebilmek için oluşturulan hipotezler aşă̆ıdaki modeller vasıtasıyla sınanmıştır. 
Model 1: ROA $_{i t}=\alpha i t+\beta_{2 i t}$ FINPOL $_{i t}+\beta_{3 i t}$ YATPOL $_{i t}+\varepsilon_{\text {it }}$

Model 2: $\mathrm{ROE}_{\mathrm{it}}=\alpha \mathrm{it}+\beta_{2 \mathrm{it}} \mathrm{FINPOL}_{\mathrm{it}}+\beta_{3 \mathrm{it}}$ YATPOL $_{\mathrm{it}}+\varepsilon_{\mathrm{it}}$

Çalışmada oluşturulan modelde, ROA ve ROE bağımlı değişkeni, FINPOL ve YATPOL bağımsız değişkenleri, $\alpha$ sabit parametreyi, $\beta_{2}$ ve $\beta_{3}$ bağımsız değişkenlerin eğim parametrelerini, i alt indisi birimleri (şirketler, birey, ülke), t alt indisi ise zamanı (gün, ay, yıl), $\varepsilon_{\text {it }}$ hata terimini ifade etmektedir (Tatoğlu, 2012: 4).

Model sınamaları için panel veri analiz yöntemi kullanılmıştır. Panel veri analizinin doğru ve tutarlı sonuçlar sağlayabilmesi ve sahte regresyon ilişsisinin ortaya çıkmaması için çeşitli varsayımların sınanması gerekmektedir. Bu varsayımlar;

$\checkmark$ Çoklu doğrusal bağlantı; Spearman Korelasyon, Varyans Şişirme Faktörü (VIF) değerleri,

$\checkmark$ Yatay kesit bağımlılı̆̆1; zaman boyutu T(28) yatay kesit boyutundan N(16) büyük çıktığı için Pesaran, Ullah ve Yagamata (2008) LMadj testi,

$\checkmark$ Homojenlik-Heterojenlik; Pesaran ve Yamagata (2008) delta testleri,

$\checkmark$ Durağanlık (birim kök testi); yatay kesit bağımlılığını dikkate almayan ve heterojen yapıda olan birinci nesil birim kök testi olan Im, Pesaran ve Shin testi, yatay kesit bağımlılığını dikkate alan ikinci nesil birim kök testi olan Smith vd. Boostrap testi,

$\checkmark$ Tahmin modeli seçimi; F testi, Breuch-Pagan LM (1980) ve Honda (1985) testleri,

$\checkmark$ Değişen varyans varsayımı Breusch-Pagan-Godfrey LM testleri,

$\checkmark$ Otokolerasyon varsayımı ise Baltagi ve Li (1991), Born ve Bretuing (2016), Durbin-Watson testleri ile sınanmıştır.

Panel veri analizi doğrultusunda model tahminine yönelik otokorelasyon ve değişen varyans varsayımları altında, White period ve Period SUR panel standart hataların düzeltilmesi yöntemleri ile tahminleme yapılmıştır. Ardından otokolerasyon sorununun çözümü için AR(1) ve $\operatorname{AR}(2)$ yöntemi kullanılmıştır.

\section{Bulgular}

Çalışma sermayesi yönetiminin finansal performansa etkisini belirlemeye yönelik gerçekleştirilen panel veri analizi sonucunda elde edilen bulgular ve bu bulgular kapsamında 
yapılan değerlendirmeler aşağıdaki tablolarda sunulmuştur. Bağımlı ve bağımsız değiş̧kenlere ilişkin tanımlayıcı istatistik değerleri hesaplanarak Tablo 3 ’te gösterilmiştir.

Tablo 3

Tanımlayıcl Istatistikler

\begin{tabular}{lcccc}
\hline & ROA & ROE & IP & FP \\
\hline Ortalama & 0.057819 & 0.122087 & 0.515745 & 0.324053 \\
Medyan & 0.047549 & 0.104452 & 0.524797 & 0.303458 \\
Maximum & 0.335877 & 0.639469 & 0.796547 & 0.796584 \\
Minimum & 0.000000 & 0.000000 & 0.227781 & 0.055850 \\
Stan.Sap. & 0.051038 & 0.101912 & 0.133687 & 0.166679 \\
Çarp1kl1k & 1.587389 & 1.396521 & -0.179930 & 0.440668 \\
Basıklık & 6.761895 & 6.176648 & 1.965161 & 2.459063 \\
Jarque-Bera & 452.3133 & 333.9872 & 22.40730 & 19.96150 \\
Olasilık & 0.000000 & 0.000000 & 0.000014 & 0.000046 \\
Gözlem & 448 & 448 & 448 & 448 \\
\hline
\end{tabular}

Tabloda; Aktif Karlılık (ROA), Özsermaye Karlılı̆ı (ROE), Yatırım Politikası (IP) ve Finansman Politikası (FP) ile ifade edilmektedir.

Tanımlayıcı istatistik sonuçlarına göre, ele alınan değişkenlerin 2005-2018 yıllarına ait 16 firmanın 14 yıllık ve altışar aylık veriler doğrultusunda 448 gözlem değeri esas alınmıştır. Bağımsız değişkenler olan yatırım politikasının ortalama değerleri 0.515 iken, finansman politikasının ise ortalama değeri 0.324 olduğu gözlemlenmiştir. Bu durum firmaların daha çok dönen varlıklara yöneldiklerini göstermektedir. Firmaların aktifinde bulunan aktif karlılık oranının ortalama değerinin 0.057 olduğu tespit edilmiştir. Özsermaye karlılığı oranının ortalaması ise 0.122 olduğu görülmüştür. Buna göre, firmaların kaynaklarını verimli kullandıkları ve kar sağlayabildikleri söylenebilir. Standart sapma değerlerine göre ise değişkenlerin ortalamadan sapma düzeylerinin düşük olduğunu söylemek mümkündür. Basıklık, çarpıklık ve Jarque-Bera olasılık değerlerine bakıldığında ise serilerin normal dağılım sergilemediği belirlenmiştir. Bu nedenle çoklu doğrusal bağlantı ve içsellik sorunlarının var olup olmadığı, normal dağılımın sağlanamadığı durumda kullanılan Spearman korelasyon testi ile tespit edilmiştir.

Çoklu doğrusal bağlantı, bağımsız değişkenlerin bir bölümü veya tümü arasında güçlü bir ilişkinin olmasını ifade etmektedir. Çoklu doğrusal bağlantı olduğu zamanlarda standart sapmaları sonsuz ve değişkenlerin katsayıları belirsiz olmasının yanında modelin açıklayıcı gücü kısaca $\mathrm{R}_{2}$ değeri çok yüksek çıkması durumunda bağımsız değişkenler anlamsız çıkabilmektedir. Bundan 
dolayı ilk olarak bağımsız değişkenler arasında çoklu doğrusal bağlantı probleminin varlığına bakılması gerekmektedir. Bu bağlamda, Spearman Korelasyon testinde bağımsız değişkenler arasındaki ilişki seviyesinin $0.75^{\prime}$ ten ve VIF (Varyans Şişirme Faktörü) değerinin 10'dan yüksek olması durumunda çoklu doğrusal bağlantı probleminin olduğunu göstermektedir (Topaloğlu, 2019). Spearman korelasyon ilişkin analiz sonuçları Tablo 4'te gösterilmektedir

Tablo 4

Spearman Korelasyon Test Sonuçları

\begin{tabular}{crrrr}
\hline & \multicolumn{1}{c}{ ROA } & ROE & IP & FP \\
\cline { 2 - 5 } ROA & 1.000000 & & & \\
& ---- & & & \\
& ---- & & & \\
IP & 0.910835 & 1.000000 & & \\
& 46.60144 & ---- & & \\
& 0.0000 & ---- & -000000 & 1.000000 \\
FP & -0.087322 & 0.045003 & ----- & ---- \\
& -1.851204 & 0.951377 & 0.497197 & ---- \\
\hline
\end{tabular}

Korelasyon test sonuçları incelendiğinde çalışmada bağımsız değişkenler arasındaki korelasyon katsayısının 0.49 olduğu sonucuna ulaşılmıştır. Bu bağlamda bağımsız değişkenler arasında çoklu doğrusal bağlantı problemi bulunmamaktadır. VIF değerlerin testine ilişkin analiz sonuçları Tablo 5 'te sunulmaktadır. Diğer taraftan bağımlı değişkenler ile bağımsız değiş̧kenler arasındaki korelasyon katsayısının ise 0.29 olduğu belirlenmiştir. Dolayısıyla, modellerde içsellik sorununa da rastlanılmamışıtır.

Tablo 5

VIF (Varyans Şişirme Faktörü) Değerleri

\begin{tabular}{lccc}
\hline \multicolumn{4}{c}{ MODEL 1 ROA } \\
\hline Değişken & IP & FP & C \\
Varyans Katsayısı & 0.000385 & 0.000248 & $8.20 \mathrm{E}-05$ \\
Merkezi olmayan VIF & 21.22440 & 6.385166 & 15.91666 \\
Merkezi VIF & 1.333496 & 1.333496 & NA \\
\hline
\end{tabular}




\begin{tabular}{lccc}
\hline \multicolumn{4}{c}{ MODEL 2 ROE } \\
\hline Değişken & IP & FP & C \\
Varyans Katsayısı & 0.001727 & 0.001111 & 0.000368 \\
Merkezi olmayan VIF & 21.22440 & 6.385166 & 15.91666 \\
Merkezi VIF & 1.333496 & 1.333496 & NA \\
\hline
\end{tabular}

Tablo 5'te sunulan VIF değerleri incelendiğinde, Model 1 ve 2 VIF testleri sonucunda, çalışmada bulunan bağımsız değişkenlerin VIF değerlerinin 1.333496 olduğu saptanmıştır. Bağımsız değişkenlere ait VIF değerlerinin kritik değer olarak kabul edilen 10'dan küçük olması ile bağımsız değişkenler arasında çoklu doğrusal bağlantı problemi olmadığı tespit edilmiştir. Bu bulgular, Spearman Korelasyon sonuçlarını da desteklemektedir.

Bir firmada ortaya çıkabilecek bir şokun diğer firmaları etkilemesine yatay kesit bağımlılığı denilmektedir. Yatay kesit bağımlılı̆̆ı seriler arasında dikkate alındığında, analizin sürdürülebilmesi için güvenirliğini büyük ölçüde etkileyebilmektedir. $\mathrm{Bu}$ doğrultuda, analizde kullanılan tüm değişkenlere LM (Breusch, Pagan 1980), CDlm (Pesaran 2004), CD (Pesaran 2004) ve LMadj (PUY, 2008) testlerinin kullanılmasına ilişkin yatay kesit bağımlılığı sonuçları, Tablo 6'da gösterilmektedir.

Tablo 6

Yatay Kesit Bă̆ımlılı̆̆ı Test Sonuçları

\begin{tabular}{cccccc}
\hline & & $\begin{array}{c}\text { LM } \\
\text { (Breusch, Pagan 1980) }\end{array}$ & $\begin{array}{c}\text { CDIm } \\
\text { (Pesaran 2004) }\end{array}$ & $\begin{array}{c}\text { CD } \\
\text { (Pesaran 2004) }\end{array}$ & $\begin{array}{c}\text { Lmadj } \\
\text { (PUY, 2008) }\end{array}$ \\
\hline \multirow{2}{*}{ ROA } & İstatistik & 179.088 & 3.814 & -2.807 & 3.792 \\
& Olasılık & 0.000 & 0.000 & 0.002 & 0.000 \\
\multirow{2}{*}{ ROE } & İstatistik & 175.314 & 3.571 & -2.701 & 8.985 \\
& Olasılık & 0.001 & 0.000 & 0.003 & 0.000 \\
\multirow{2}{*}{ IP } & İstatistik & 239.638 & 7.723 & -2.616 & 1.297 \\
& Olasılık & 0.000 & 0.000 & 0.004 & 0.097 \\
FP & İstatistik & 174.050 & 3.489 & -2.344 & 0.068 \\
& Olasilık & 0.001 & 0.000 & 0.010 & 0.473 \\
\hline
\end{tabular}

Not: $\mathrm{H}_{0}$ : Yatay kesit bağımlılığı yoktur. $\mathrm{H}_{1}$ : Yatay kesit bağımlılığı vardır. $(\% 5$ olasılık değeri ile değerlendirilmektedir.

Yatay kesit bağımlılığı test sonuçlarına göre zaman boyutu yatay kesit boyutundan yüksek olduğu için LMadj Pesaran, Ullah ve Yamagata (2008) test sonuçları dikkate alınmıştır. LMadj 
Pesaran, Ullah ve Yamagata (2008) testi IP ve FP olasılık değerleri 0.05 'ten büyük çıktığı tespit edilmiştir. Dolayısıyla " $\mathrm{H}_{0}$ : yatay kesit bağımlılı̆̆ı yoktur." $\mathrm{H}_{0}$ reddedilememiştir ve yatay kesit bağımlılığı yoktur. ROA ve ROE olasılık değerleri 0.05 'ten küçük olduğu için $\mathrm{H}_{0}$ hipotezi reddedilmiştir. Dolayısıyla, ROA ve ROE değişkenlerinde yatay kesit bağımlılığı olduğu tespit edilmiştir. Yatay kesit bağımlılığı sonrasında, durağanlığın test edilebilmesi için hangi birim kök testinin kullanılması gerektiği, yatay kesit bağımlılığı ve homojenite test sonuçları ile belirlenmektedir. Pesaran ve Yamagata (2008) Delta testleri ile her bir firma için eğim katsayılarının ve sabit terimleri homojen mi yoksa heterojen mi olduğu araştırılmıştır. Tablo 7'de yapılan Homojenite testine ilişkin sonuçlar aşağıda sunulmaktadır.

Tablo 7

Homojenite Test Sonuçlarl

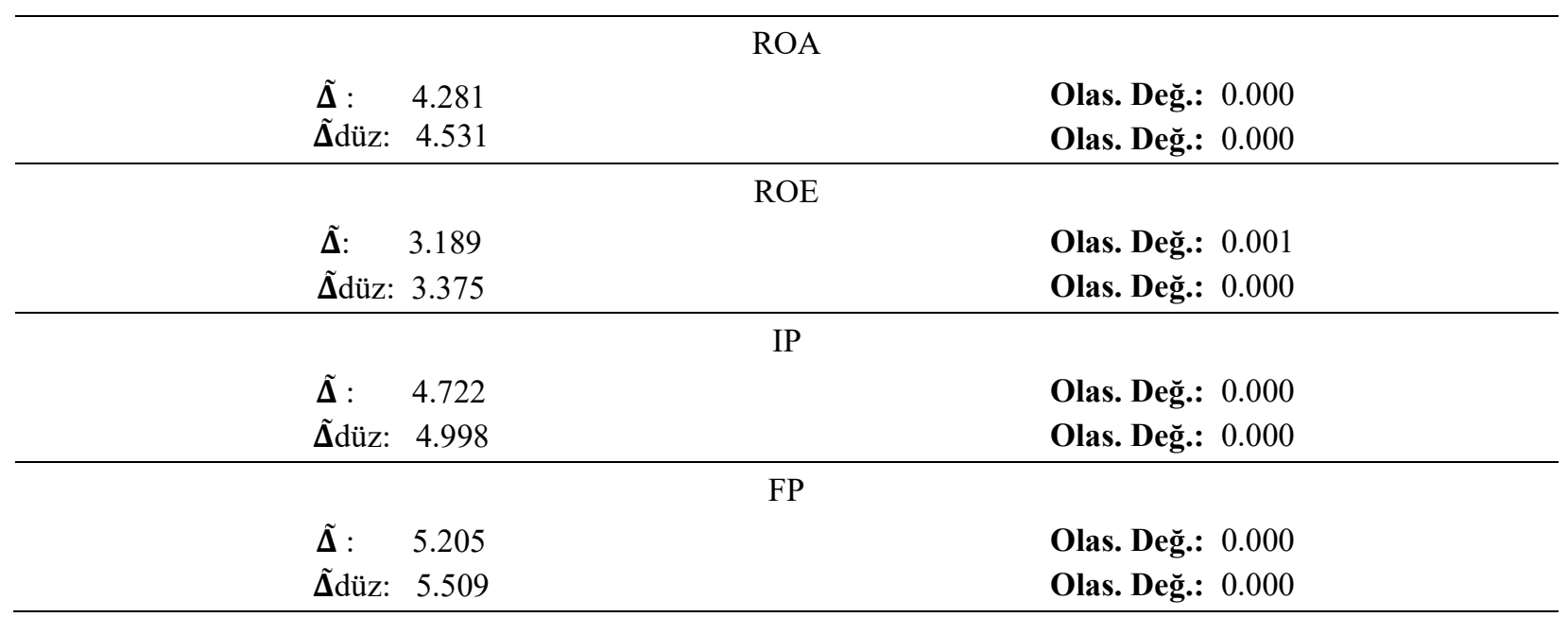

Not: $\mathrm{H}_{0}$ : Seriler homojendir $\mathrm{H}_{1}$ : Seriler heterojendir. (\% 5 olasılık değeri ile değerlendirilmektedir.)

Homojenlik testi sonucuna göre, ROA, ROE, IP ve FP değişkenleri olasılık değerleri 0.05 'ten küçük olduğundan “ $\mathrm{H}_{0}$ : Seriler homojendir." $\mathrm{H}_{0}$ hipotezi reddedilir ve seriler heterojendir. Dolayısıyla elde edilen analiz sonuçlarına göre; ROA ve ROE değişkenleri yatay kesit bağımlılığını dikkate alan ve heterojen bir yapıda olduğu, IP ve FP değişkenlerinin ise yapılan testlerde yatay kesit bağımlılığı olmadığı ve heterojen bir yapıya sahip olduğu tespit edilmiştir.

Panel veri analizinin gerçekleştirilebilmesi ve değişkenler arasında anlamlı sonuçların elde edilebilmesi için serilerin durağan olmaları gerekmektedir. Çalışmada, yatay kesit bağımlılığı söz konusu olduğunda ve heterojen yapıya sahip olan ROA ve ROE değişkenleri için ikinci nesil birim kök testlerinden biri olan Smith vd. Boostrap testi kullanılırken, yatay kesit bağımlılı̆ğ söz konusu 
olmadığında ve heterojen bir yapıya sahip olan IP ve FP değişkenlerinin durağanlıklarını test edebilmek için birincil nesil birim kök testlerinden biri olan Im, Pesaran ve Shin (IPS) testi kullanılmıştır. Im, Pesaran ve Shin testi sonuçları aşağıda Tablo 8'de gösterilmektedir.

Tablo 8

Im, Pesaran ve Shin Testi Sonuçlart

\begin{tabular}{|c|c|c|}
\hline \multirow{3}{*}{ Sabit } & \multicolumn{2}{|c|}{$\begin{array}{c}\text { FP } \\
\text { W-İstatistik }\end{array}$} \\
\hline & İstatistik & -3.04651 \\
\hline & Olasılık & 0.0012 \\
\hline \multirow{3}{*}{ Sabit ve Trend } & & \\
\hline & İstatistik & -4.59771 \\
\hline & Olasılık & 0.0000 \\
\hline \multirow{3}{*}{ Sabit } & & \\
\hline & İstatistik & -3.55258 \\
\hline & Olasılık & 0.0002 \\
\hline \multirow{3}{*}{ Sabit ve Trend } & & \\
\hline & İstatistik & -2.28373 \\
\hline & Olasılık & 0.0112 \\
\hline
\end{tabular}

Not: $\mathrm{H}_{0}$ : Seri durağan değildir. $\mathrm{H}_{1}$ : Seri durağandır (\%5 olasılık değeri ile değerlendirilmektedir).

Tablo 8'de Im, Pesaran ve Shin testi sonuçları değerlendirildiğinde, IP ve FP değişkenlerine yönelik olasılık değerleri 0.05 'ten küçük çıkmıştır. Böylelikle $\mathrm{H}_{0}$ hipotezi reddedilmiştir. Kısaca birim kök yoktur ve seriler durağandır. İkinci nesil birim kök testlerinden biri olan Smith vd. (2004) Boostrap testine yönelik birim kök testi analiz sonuçları Tablo 9' da gösterilmektedir.

Tablo 9

Smith vd. (2004) Boostrap Birim Kök Test Sonuçları

\begin{tabular}{rcccc}
\hline & t-bar istatistik & Olasilı Değeri & WS istatistik & Olasilık \\
ROA & -2.219 & 0.005 & -2.377 & 0.000 \\
Sabit & -2.856 & 0.002 & -3.101 & 0.000 \\
Sabit ve trend & & & & 0.000 \\
ROE & -2.369 & 0.000 & -2.556 & 0.000 \\
Sabit & -3.048 & 0.000 & -3.423 & \\
\hline Sabit ve trend & & & & \\
\hline
\end{tabular}

$\mathrm{H}_{0}$ : Seri durağan değildir. $\mathrm{H}_{1}$ : Seri durağandır (\%5 olasılık değeri ile değerlendirilmektedir). 
Smith vd. (2004) Boostrap test sonuçları incelendiğinde, olasılık değerleri 0.05'ten küçük çıkmıştır ve $\mathrm{H}_{0}$ hipotezi reddedilmiştir, yani serilerde birim kök yoktur. Diğer bir deyişle, ROA ve ROE değişkenlerine ilişkin serilerin durağan olduğu belirlenmiştir.

Sabit etkiler, rassal etkiler ve havuzlanmış modelden hangisinin tahminleme için kullanılacağına F testi, LM (1980) ve Honda (1985) testleri ile karar verilmesi ve modellerde grup ve/veya zaman etkilerinin olup olmadığı sınanmıştır. Hangi tahminleme modelinin kullanılacağ tespit edildikten sonra değişen varyans ve otokolerasyon varsayımları incelenmiştir. Analiz sonuçları Tablo 10’da gösterilmektedir.

Tablo 10

Sabit - Rassal Etkiler Model Belirleme Analiz Sonuçları (ROA)

\begin{tabular}{lcc}
\hline Test & İstatistik & p-değeri \\
\hline F-grup_sabit & 8.967399 & 0.000000 \\
F-zaman_sabit & 5.535867 & 0.000000 \\
F-iki yönlü_sabit & 6.682005 & 0.000000 \\
\hline LM-grup_rassal & 135.6202 & 0.000000 \\
LM-zaman_rassal & 86.74584 & 0.000000 \\
LM-iki yönlü_rassal & 222.3660 & 0.000000 \\
\hline Honda-grup_rassal & 11.64561 & 0.000000 \\
Honda-zaman_rassal & 9.313745 & 0.000000 \\
Honda-iki yönlü_rassal & 14.82050 & 0.000000 \\
\hline Değişen Varyans İçin Çift Yönlü Sabit Etkiler Model & 249.2552 & 0.000000 \\
Testi & & \\
LMh_sabit & & \\
Otokorelasyon Testi & & 0.000000 \\
\hline LMp-İstatistik & 78.38339 & 0.000000 \\
LMp*-İstatistik & 92.97993 & \\
Durbin-Watson & 1.108956 & \\
\hline Ho: Otokolerasyon yoktur. & $\mathrm{H}_{0}$ : Değişen varyans yoktur. \\
H: Otokolerasyon vardır. & $\mathrm{H}_{1}$ : Değişen varyans vardir. \\
\hline
\end{tabular}

Model 1 için sonuçlar incelendiğinde, havuzlanmış model ile sabit etkiler modeli arasında seçim yapılabilmesi için yapılan $F$ testi sonucuna göre, hesaplanan olasılık değeri \%5'ten küçük olduğu için $\mathrm{H}_{0}$ hipotezi reddedilmektedir. Dolayısıyla, ROA esas alınarak oluşturulan Model 1'de zaman ve grup etkilerinin olduğu çift yönlü sabit etkiler modeli geçerlidir. Havuzlanmış model ile mi yoksa rassal etkiler modeli arasında hangisinin kullanılması gerektiğinin tespit edilebilmesi için, LM ve Honda testleri yapılmış ve elde edilen sonbuçlara göre rassal etkiler modelinin kullanılmasının daha etkin sonuçlar vereceği saptanmıştır. Ayrıca grup ve/veya zaman etkisine 
bakıldığında ise olasılık değeri kritik değerinin altında olduğu için çift yönlü etkinin geçerli olduğu tespit edilmiştir. Ancak bu araştırmada incelenen dönem ve firmalar dikkate alındığında, belirli bir dönemde ve belirli bir firma grubunu içerdiği için sabit etkiler modeli ile tahminleme yapılması, daha etkin ve tutarlı sonuçlar sağlanması açısından önemlidir. Modelde hata terimine ilişkin değişen varyans ve otokolerasyon varsayımlarının sınanması gerekmektedir. Tabloya göre, sabit etkiler modeli baz alındığında otokolerasyon Baltagi ve Li (1991) LM istatistik, Born ve Breuting (2016) LM istatistik ve Durbin Watson testleri ile test edilirken, değişen varyans için ise BreuschPagan-Godfrey LM testi ile test edilmiştir. Değişen varyans ve otokolerasyon testinin sonuçları değerlendirildiğinde ise, olasılık değeri kritik değerin altında olduğu için değişen varyans ve otokolerasyon sorunlarının olduğu tespit edilmiştir (Topaloğlu, 2018: 28). Tablo 11'de ROE için Model 2 sonuçları gösterilmektedir.

Tablo 11

Sabit - Rassal Etkiler Model Belirleme Analiz Sonuçları (ROE)

\begin{tabular}{lcc}
\hline Test & İstatistik & p-değeri \\
\hline F-grup_sabit & 8.967399 & 0.000000 \\
F-zaman_sabit & 5.535867 & 0.000000 \\
F-iki yönlü__sabit & 6.682005 & 0.000000 \\
\hline LM-grup_rassal & 135.6202 & 0.000000 \\
LM-zaman_rassal & 86.74584 & 0.000000 \\
LM-iki yönlü_rassal & 222.3660 & 0.000000 \\
\hline Honda-grup_rassal & 11.64561 & 0.000000 \\
Honda-zaman_rassal & 9.313745 & 0.000000 \\
Honda-iki yönlü_rassal & 14.82050 & 0.000000 \\
\hline Değişen Varyans İçin Çift Yönlü Sabit Etkiler Model Testi & 249.2552 & 0.000000 \\
LMh_sabit & & \\
Otokorelasyon Testi & & \\
\hline LMp-İstatistik & 78.38339 & 0.000000 \\
LMp*-İstatistik & 92.97993 & 0.000000 \\
Durbin-Watson & 1.108956 & \\
\hline Ho Otokolerasyon yoktur. & $\mathrm{H}_{0}:$ Değişen varyans yoktur. \\
$\mathrm{H}_{1}$ : Otokolerasyon vardır. & $\mathrm{H}_{1}:$ Değişen varyans vardir. \\
\hline
\end{tabular}

Tablo 11'deki sonuçlar değerlendirildiğinde, F testi sonucuna göre, sabit etkiler modeli ile tahminleme yapılması gerektiği belirlenmiştir. Grup ve/veya zaman etkisine bakıldığında ise çift yönlü etkinin kısaca hem zaman hem de grup etkisi geçerli olduğu saptanmıştır. LM ve Honda testi incelendiğinde, rassal etkiler modeli ile tahminleme yapılabileceği de belirlenmiştir. Ancak bu araştırmada incelenen dönem ve firmalar dikkate alındığında, belirli bir dönemde ve belirli bir firma grubunu içerdiği için sabit etkiler modelinin kullanılması, daha tutarlı ve etkin sonuçlar elde 
edilmesi bakımından önemlidir. Modelde hata terimine ilişkin değişen varyans ve otokolerasyon varsayımlarının sınanması gerekmektedir. Tabloya göre, Model 2'de sabit etkiler modeli baz alındığından değişen varyans ve otokolerasyon testinin sonuçları değerlendirildiğinde, değişen varyans ve otokolerasyon sorununun olduğu tespit edilmiştir. Dolayısıyla değişen varyans ve otokolerasyon problemini giderebilmek için White Period ve Periyot SUR yöntemi panel standart hataların düzeltilmesinde kullanılmıştır. Ardından AR(1) ve AR(2) sürecinin kullanılmasıyla otokolerasyon problemi çözülmesini sağlamıştır. Tahmin sonuçları, Tablo 12'de gösterilmektedir.

Tablo 12

Model 1 Tahmin Sonuçları (ROA)

\begin{tabular}{|c|c|c|c|c|}
\hline Değişkenler & Katsayı & Standart Hata & t-İstatistik & Olasılık Değeri \\
\hline IP & 0.191846 & 0.043754 & 4.384603 & 0.0000 \\
\hline FP & -0.067658 & 0.037401 & -1.808998 & 0.0712 \\
\hline $\mathrm{C}$ & -0.014666 & 0.030023 & -0.488489 & 0.6255 \\
\hline $\operatorname{AR}(1)$ & 0.224244 & 0.101179 & 2.216311 & 0.0272 \\
\hline $\operatorname{AR}(2)$ & 0.348502 & 0.103440 & 3.369117 & 0.0008 \\
\hline \multicolumn{5}{|c|}{ White Periyot } \\
\hline R- kare & 0.401171 & \multicolumn{2}{|l|}{ Ort. Bağımlı Değ. } & 0.059212 \\
\hline Düzeltilmiş R-kare & 0.372439 & \multicolumn{2}{|c|}{ S. S. Bağımlı Değ. } & 0.051722 \\
\hline S.E. of regresyon & 0.040974 & \multicolumn{2}{|c|}{ Akaike Bilgi Kriteri } & -3.504897 \\
\hline Resid Kare Ort. & 0.664818 & \multicolumn{2}{|c|}{ Schwarz Bilgi Kriteri } & -3.311114 \\
\hline Log likelihood & 749.0185 & \multicolumn{2}{|c|}{ Hannan-Quinn Bilgi Kriteri. } & -3.428275 \\
\hline F-İstatistik & 13.96265 & & & \\
\hline Olasılık (F-İstatistik) & 0.000000 & & & \\
\hline Inverted AR Roots & .71 & -.49 & & \\
\hline
\end{tabular}

Model 1 ROA tahmin sonuçlarına göre, modelin anlamlı olup olmadığını gösteren (Fistatistik) olasılık değeri 0.05 'ten küçük çıktığı tespit edilmiştir. Böylece aktif karlılık temel alınarak oluşturulan modelin bir bütün olduğu, \%1 anlamlılık düzeyinde modelin anlamlı olduğu belirlenmiştir. Çalışma sermayesi yatırım ve finansman politikası olan bağımsız değişkenlerin, bağımlı değişken olan aktif karlılıkta (ROA) meydana gelen değişimlerin 0.37 'sini açıkladığı tespit edilmiştir. Model 1'de elde edilen bulgular incelendiğinde, çalışma sermayesi yatırım politikası ile aktif karlılık arasında anlamlı ve pozitif bir ilişki tespit edilmiştir. Yatırım politikasındaki bir birimlik artış aktif karlılıkta 0.19 birimlik bir artışa neden olmaktadır. Bu bağlamda toplam varlıklar içerisindeki dönen varlıkların artması aktif karlılığı yükseltmektedir. Diğer bir ifade ile firmalar yatırım politikasını izleyerek firmanın karlılığını artırabilmektedir. Bu durum ihtiyatlı 
politikanın uygulanması doğrultusunda, firmalar finansal sıkıntı ve iflas maliyetleri ile karşılaşmamakta aksine karlılıkları da artmaktadır. Finansman politikası (FP) ile aktif karlılık (ROA) arasında ise istatistiksel olarak anlamlı ve negatif bir ilişki tespit edilmiştir. Diğer taraftan finansman politikasındaki bir birimlik artış ise aktif karlılıkta 0.06 birimlik bir azalışa neden olmaktadır. Toplam kaynaklar içerisinde kısa vadeli kaynakların fazla kullanılması, firmanın atılgan bir tutum sergilemesine neden olduğu gözlemlenmektedir. Bu durum firmaların karlılığını da düşürdügü de görülmektedir. Çünkü firmalar maliyetten kaçınmak isterken elde ettikleri karı da kaybetme durumu ile karşılaşabilmektedir. Bu bulgular doğrultusunda araştırmada oluşturulan Hipotez 1 ve Hipotez 2 reddedilmiştir. Tablo 13'te yer alan Model 2 ROE tahmin sonuçları aşağıda gösterilmektedir.

Tablo 13

Model 2 Tahmin Sonuçları (ROE)

\begin{tabular}{lcccc}
\hline Değişkenler & Katsayı & Standart Hata & t-İstatistik & Olasılık Değeri \\
\hline IP & 0.462072 & 0.073646 & 6.274222 & 0.0000 \\
FP & -0.084603 & 0.069586 & -1.215802 & 0.2248 \\
C & -0.074932 & 0.047740 & -1.569592 & 0.1173 \\
AR(1) & 0.245168 & 0.062620 & 3.915204 & 0.0001 \\
AR(2) & 0.443079 & 0.068372 & 6.480382 & 0.0000 \\
\hline \multicolumn{5}{c}{ Periyot SUR (PCSE) } \\
\hline R- kare & 0.417871 & & 0.125065 \\
Düzeltilmiş R-kare & 0.389940 & Ort. Bağımlı Değ. & 0.102853 \\
S.E. of regresyon & 0.080335 & S. S. Bağımlı Değ. & -2.158339 \\
Resid Kare Ort. & 2.555673 & Akaike Bilgi Kriteri & -1.964556 \\
Log likelihood & 468.9345 & Schwarz Bilgi Kriteri & -2.081718 \\
F-İstatistik & 14.96113 & Hannan-Quinn Bilgi Kriteri. & \\
Olasılık (F-İstatistik) & 0.000000 & & & \\
Inverted AR Roots & .80 & -.55 & \\
\hline
\end{tabular}

Model 2 ROE tahmin sonuçlarına göre, modelin anlamlı olup olmadığını gösteren (Fistatistik) olasılık değeri 0.05 ’ten küçük çıktığı tespit edilmiştir. Böylece özsermaye karlılığı temel alınarak oluşturulan modelin bir bütün olduğu, \%1 anlamlılık düzeyinde anlamlı olduğu görülmektedir. Çalışma sermayesi yatırım ve finansman politikası olan bağımsız değişkenlerin, bağımlı değişken olan özsermaye karlılığında (ROE) meydana gelen değişimlerin yaklaşık 0.39'unu açıkladığı tespit edilmiştir. Model 2'de elde edilen bulgular incelendiğinde, çalışma sermayesi yatırım politikası ile özsermaye karlılığı arasında anlamlı ve pozitif bir ilişki tespit 
edilmiştir. Yatırım politikasındaki bir birimlik artış özsermaye karlılığında 0.46 birimlik artışa neden olmaktadır. Bu bağlamda firmalar yatırım politikasını izleyerek özsermaye karlılığını arttırmaktadır. Böylece dönen varlıklara yapılan yatırımın fazla olması firma karlılığını da olumlu olarak etkileyebilmektedir. Diğer taraftan çalışma sermayesi finansman politikası ile özsermaye karlılığı arasında anlamlı bir ilişki tespit edilememiştir. Çalışmada elde edilen bu sonuçlar Raheman, vd. (2010), Salawu (2007), Nur Topaloğlu (2019), Şahin (2011), Öndeş \& Pagheh (2018), Mwangi vd. (2014), Nazir \& Afza (2009) yapılan çalışmalar ile bulunan sonuçlar paralellik, Lazaridis \& Tryfonidis (2006), Taani (2012), Şamiloğlu \& Demirgüneş (2008) (2017), Al-Shubiri (2011) Bhatia \& Srivastava (2016) ile de farklılık göstermektedir. Araştırmada oluşturulan Hipotez 3 reddedilemezken, Hipotez 4 ise reddedilmiştir.

\section{Sonuç}

Firmaların devam eden faaliyetlerini daha uzun vadede sürdürebilmek ve yeni yatırımlara yönelebilmesi için çalışma sermayesi yönetiminin sağlıklı bir biçimde yerine getirilmesi gerekmektedir. Firmalar, karlılığını ve piyasadaki varlığını koruyarak en üst seviyeye getirmeyi hedeflemektedir. Buna karşın; firmalar için üretimin kesintisiz sürdürülmesi, kriz döneminde yaşanan dalgalanmalarda varlığını devam ettirebilmesi, borçlarını vadesinde ödeyebilmesi, faaliyetlerini başarılı ve karlı bir biçimde yerine getirebilmesi için çalışma sermayesi yönetimi önem arz etmektedir. Firmaların aldıkları finansal kararları, ekonomik koşulları, teknolojik değişmeleri, üretim kapasitesi, firmanın finansal durumu, geleceğe yönelik hedefleri ve yapılacak olan yatırımları çalışma sermayesi yönetimini etkileyebilmektedir.

Çalışmada, 2005-2018 döneminde BIST 100 endeksinde kesintisiz işlem gören firmaların, çalışma sermayesi yönetiminin finansal performansa etkisinin ortaya çıkarılması amaçlanmıştır. Bu doğrultuda, çalışma sermayesi yönetiminin finansal performans üzerindeki etkisini araştırmak için panel veri analizi yöntemi kullanılmıştır. Araştırmada bağımsız değişken olarak yatırım ve finansman politikaları belirlenirken, bağımlı değişken olarak ise aktif karlılık ve özsermaye karlılığı belirlenmiştir. Finansal performansı temsil eden değişkenler doğrultusunda iki farklı model kurulmuştur.

Model 1 ROA analiz neticesinde, \%1 anlamlılık düzeyinde modelin anlamlı olduğu belirlenmiş, yatırım ve finansman politikasının aktif karlılıkta (ROA) meydana gelen değişimlerin yaklaşık olarak 0.38 'ini açıkladığı tespit edilmiştir. Analizde, yatırım politikası ile aktif karlılık 
arasında anlamlı ve pozitif yönlü bir ilişki tespit edilmiştir. Toplam aktifler içerisinde dönen varlıkların artması, aktif karlılığı yükselttiği sonucuna ulaşılmaktadır. Bu durumda firmalar ihtiyatlı bir yol izlemektedir. Finansman politikası ile aktif karlılık arasında ise anlamlı ve negatif bir ilişki belirlenmiştir. Toplam kaynaklar içerisinde kısa vadeli kaynak kullanımının artması aktif karlılığı olumsuz olarak etkilediği tespit edilmiştir. Bu durumda atılgan finansman politikasını benimseyen firmaların başarılarını düşürdüğü sonucuna varılmıştır.

Model 2 ROE analiz sonucunda ise, \%1 anlamlılık düzeyinde modelin anlamlı olduğu tespit edilmiş, yatırım ve finansman politikasının özsermaye karlılığında (ROE) meydana gelen değişimlerin yaklaşık 0.39'unu açıkladığı belirlenmiştir. Model 2'de yatırım politikası ile özsermaye karlılığı arasında anlamlı ve pozitif bir ilişki tespit edilmiştir. Toplam aktifler içerisindeki dönen varlıklardaki artışın özsermaye karlılığını olumlu etkilediği görülmektedir. Buna göre firma, yeni yatırımlara yönelerek kendi içinde bıraktığı karı daha fazla yükseltmektedir. Finansman politikası ile özsermaye karlılığı arasında anlamlı bir ilişki tespit edilememiştir.

Araştırma kapsamında oluşturulan Hipotez 1, 2 ve 4 reddedilirken, Hipotez 3 reddedilememiştir. Bu çalışmada elde edilen bulgular; Raheman, vd. (2010), Nur Topaloğlu (2019), Şahin (2011), Öndeş \& Pagheh (2018), Mwangi vd. (2014), Nazir \& Afza (2009) tarafından elde edilen bulguların sonuçları ile paralellik göstermektedir. Firmalarda çalışma sermayesi yönetiminin finansal performansı etkilediği belirlenmiştir.

Çalışmada elde edilen bulgular doğrultusunda, dönen varlıklara daha fazla yatırım yapan firmaların karlılığına olumlu bir etki yarattığı ve piyasadaki varlıklarını koruduğu gözlemlenmektedir. Buna karşın, yapılan yatırımın yükselmesi ile fonların fazlalaşmasından dolayı çalışma sermayesinde sıkıntı yaşanmamasını sağlayabilmektedir. Dolayısıyla, elde edilen yatırım fırsatlarının değerlendirilmesi, firmaların karlılığını daha fazla yükseltebilmektedir. Ayrıca ihtiyatlı yatırım politikasını benimseyen firmaların çalışma sermayesini daha etkin bir biçimde yönetebildikleri söylenebilir. Dolayısıyla firmaların daha fazla kaynak kullanarak ortaya çıkan kaynak maliyetinin yüksek olduğu anlamına gelse de performansı arttırıcı etkinin yüksek olduğu görülmektedir. Bu durum firma dışarıdan aldığı borçlarla kendi finansmanını sağlamamakta ve iç kaynaklarına yönelerek karlılığını yükselmektedir. Bu durumda firma ya oto-finansmana başvurmakta ya da kendi içerisinde bıraktığı kâr payından yararlanması gerekmektedir. 
Atılgan finansman politikasının aktif karlılık üzerinde negatif etki yarattığı söylenebilir. Buna göre, kısa vadeli kaynaklardaki kullanımın artması, firmaların riskini yükseltmekte ve kaynak maliyetini yok etmektedir. Ancak firmalarda karlılığın düşmesine ve finansal performansın azaltıcı etkiye yol açtığı söylenebilir. Ayrıca atılgan finansman politikasını izleyen firmaların kaldıraç oranını yeterli bir biçimde kullanamaması, yükümlülüklerini yerine getirecek seviyede olmadığını ortaya koymaktadir.

BİST 100 endeksinden faaliyet gösteren firmaların atılgan politika yerine ihtiyatlı politika izlemeleri finansal performansları ve devamlılık açısından daha faydalı olduğu söylenebilir. Ayrıca kriz dönemlerinde ve olağanüstü hallerde ortaya çıkan dalgalanmalarda ihtiyatlı politikanın izlenmesi, firmanın finansal performansını arttırmakta ve firmaların daha başarılı bir konuma gelmesini sağlayabilmektedir. Firmalar atılgan politikayı takip ederlerse üstlendikleri risk düzeyi de yükselebilmektedir. Fakat ihtiyatlı politika takip edilirse firmaların risk düzeyi de azalabilmektedir. Buna göre, hissedarların, firma yöneticilerinin, yatırımcıların ve araştırmacıların araştırmada elde edilen bulgular sonucunda kendi menfaatleri doğrultusunda finansal kararları uygulayabilmeleri açısından önem arz etmektedir. Konuya yönelik literatürde yapılmış benzer çalışmalar ile karşılaştırıldığında; çalışmanın kapsamı, belirlenen değişkenler, uygulanan yöntem, incelenen dönem ve elde edilen bulgular doğrultusunda çalışmanın literatüre katkı sağlayacağ düşünülmektedir.

\section{Kaynakça}

Aksoy, A. \& Yalçıner, K. (2008). İşletme Sermayesi Yönetimi (4.Basım). Gazi Kitabevi: Ankara.

Al-Shubiri, F.N. (2011). Analysis of the relationship between working capital policy and operating risk: An empirical study on jordanian industrial companies. Hebron University Research Journal, 6(1), 287-306.

Bhatia, S. \& Srivastava, A. (2016). Working capital management and firm performance in emerging economies: Evidence from India. Management and Labour Studies, 41(2), 1-17.

Ceylan, A. \& Korkmaz, T. (2008). Işsletmelerde Finansal Yönetim (10. Basım). Ekin Basım Yayın Dağıtım: Bursa.

Coşkun, E. \& Kök, D. (2011). Çalışma sermayesi politikalarının karlılık üzerine etkisi: Dinamik panel uygulamas1. Ege Akademik Bakış, 11(5), 75-85.

Eljelly, A. (2004). Liquidity-profitability tradeoff: An empirical investigation in an emerging market. International Journal of Commerce \& Management, 14(2), 48 - 61. 
Filbeck, G. \& Krueger, T. M. (2005). An analysis of working capital management results across industries. American Journal of Business, 20(2), 11-20.

Kendirli, S. \& Çankaya, M. (2016). BİST turizm endeksindeki şirketlerde işletme sermayesi yönetiminin karlılık üzerindeki etkisini ölçmeye yönelik bir araştırma. International Review of Economics and Management, 4(2), 46-68.

Lazaridis, I. \& D. Tryfonidis (2006). Relationship between working capital management and profitability of listed companies in the athens stock exchange. Journal of Financial Management and Analysis, 19(1), 26-35.

Makori, D. M. \& Jagongo, A. (2013). Working capital management and firm profitability: Empirical evidence from manufacturing and construction firms listed on Nairobi Securities Exchange. International Journal of Accounting and Taxation, 1(1), 1-14.

Mwangi, W. L., Makau, S. M. \& Kosimbei, G. (2014). Effects of working capital management on performance of nonfinancial companies listed in NSE, Kenya. European Journal of Business and Management, 6(11), 195-218.

Nazir, M. S. \& T. Afza (2009). Impact of aggressive working capital management policy on firms' Profitability. IUP Journal of Applied Finance, 15(8), 19-30.

Nur Topaloğlu, T. (2019). Çalışma sermayesi yatırım ve finansman politikalarının firma karlılığına etkisi: BİST 30 firmaları üzerine panel veri analizi. International Journal of Economics, Politics, Humanities \& Social Sciences, 2(2), 89-108.

Öndeş, T. \& Pagheh, E. (2018). Firmaların işletme sermayesi stratejileri ile risk, getiri ve karlılık yetenekleri arasındaki ilişkinin incelenmesi: BİST üzerine ampirik bir çalışma. International Journal of Academic Value Studies, 4(21), 801-813.

Raheman, A., Afza, T., Qayyum A., \& Bolda, A., M. (2010). Working capital management and corporate performance of manufacturing sector in Pakistan. International Research Journal of Finance and Economics, 47(1), 151-163.

Rasyid R. (2017). Impact of the aggressive working capital management policy on firm's profitability and value: Study on non-financial listed firms in Indonesia Stock Exchange. Advances in Economics, Business \& Management Research, 36, 207-217.

Salawu, R. O. (2007). Capital industry practice and aggressive conservative working capital policies in Nigeria. Global Journal of Business Research, 1(2), 109-118.

Şahin, O. (2011). İMKB'ye kayıtlı imalat şirketlerinde çalışma sermayesi politikaları ve firma performansı ilişkileri. Eskişehir Osmangazi Üniversitesi, İktisadi ve İdari Bilimler Fakültesi Dergisi, 6(2), 123-141.

Şamiloğlu, F. \& Demirgüneş, K. (2008). The effect of working capital management on firm profitability: Evidence from Turkey. The International Journal of Applied Economics and Finance, 2(1), 44-50. 
Taani K. (2012). Impact of working capital management policy and financial leverage on financial performance: Empirical evidence from Amman Stock Exchange - Listed Companies. International Journal of Management Sciences \& Business Research, 1(8), 10-18.

Tatoğlu, Y. F. (2012). Panel Veri Ekonometrisi. Beta Yayıncılık: İstanbul.

Topaloğlu, E. E. (2018). Bankalarda finansal kırılganlığı etkileyen faktörlerin panel veri analizi ile belirlenmesi. Eskişehir Osmangazi Üniversitesi İIBF Dergisi, 13(1), 15-38.

Topaloğlu, E. E. (2019). Pay Piyasalarında Yatırımcı Duyarlılı̆̆ OECD Ülkeleri Üzerine Ekonometrik Bir Araştırma (1. Baskı). Gazi kitabevi: Ankara.

Tripathi, N. N. \& Ahamed, N. (2017). Time taken to reach the performance summit: Nature of relation between working capital management and firm performance in the Indian context. International Journal of Economics \& Financial Issues, 7(4), 530-536.

Wanguu, C. K. (2015). The effect of aggressive working capital policy on profitability of non financial firms listed at Nairobi Securities Exchange. International Journal of Commerce \& Business Studies, 3(4), 15-24.

Borsa İstanbul (www.bist.gov.tr) Erişim Tarihi: 02.09.2020

Kamuyu Aydınlatma Platformu (www.kap.gov.tr) Erişim Tarihi: 02.09.2020 